\title{
Animal Sentience and Welfare: An Overview
}

\author{
Suresh Kumar ${ }^{1 *}$, Sanjay Choudhary ${ }^{1}$, Rohit Kumar1, Alok Kumar², \\ Prasanna Pal $^{3}$ and Kanika Mahajan ${ }^{4}$ \\ ${ }^{1}$ Livestock Production Management, ICAR-NDRI Karnal, India \\ ${ }^{2}$ Animal Reproduction Gynaecology and obstetrics (Section-LPM), ICAR-NDRI Karnal, India \\ ${ }^{3}$ Animal Physiology Division, ICAR-NDRI Karnal, India \\ ${ }^{4}$ Livestock Products Technology, FVSC \& AH, SKUAST-JAMMU, India \\ *Corresponding author
}

\section{A B S T R A C T}

Animal sentience and welfare needs utmost importance as animal sentience is the capacity to feel pleasure and pain whereas, welfare would be intimately connected with the physiological stress response and it would simply be a matter of finding a

Keywords

Animal sentience,

Emotions, Pain,

Pleasure, Welfare

Article Info

Accepted:

07 July 2019

Available Online:

10 August 2019 reliable indicator of stress. Sentient animals are aware of their feelings and emotions. Animals also enjoy positive and negative emotions from carrying out natural behaviour. These could be negative feelings such as pain, frustration and fear. Sentient animals have complex social lives involving communication, organized groups and family bonds, the disruption of these relationships can severely damage animal welfare - Separating bonded individuals like a mother and infant can cause the animals to protest and despair. Sentience like feelings can be measured directly or indirectly by the methods such as preference testing, motivational testing and understanding animal communication. However, sentience as a science have limitations like anthropomorphism, cognition and demonstrating its existence at a scientific level is that the concept relates to a being's own thoughts, feelings and emotions. From, this study it may be concluded that animal sentience is imperative for improving animal welfare and attitudes towards animals.

\section{Introduction}

Sentience is the ability to perceive and feel things. An animal is sentient if it is capable of being aware of its surroundings, its relationships with other animals and humans and of sensations in its own body, including pain, hunger, heat or cold (Turner et al.,
2006). In 2012, an international group of eminent neuroscientists signed the Cambridge Declaration on Consciousness, which confirmed that many animals, including all mammals and birds, possess the "neurological substrates that generate consciousness" (Low et al., 2012). It is logical to suppose that sentient animals also enjoy feelings of 
comfort, enjoyment, contentment and perhaps even great delight and joy. A sentient animal is "a being who has interests; that is, a being who prefers, desires or wants" (Francione et al., 2012). These animals naturally try to avoid suffering and seek positive experiences (Webster et al., 2005) just like humans. Animals have evolved to cope as successfully as possible with life in the wild. Thousands of years of domestication of farm animals have changed their basic motivations and behaviour patterns very little. Industrial-type farming often fails to appreciate animals' needs and their capacity to suffer. This can mean that very large numbers of sentient animals are routinely subjected to pain and deprivation. Globally each year we farm 70 billion farm animals for meat, milk or eggs. The majority of commercially-farmed animals are confined in cages, narrow stalls or in overcrowded sheds. In such confinement, there is little or no opportunity to carry out the natural behaviours which are so important to them. It is urgent that farming systems and practices adopt methods which recognise animal sentience and pay full regard to the animals' needs.

Scientists believe that sentience is necessary because it helps animals to survive by:

Learning more effectively from experience in order to cope with the world.

Distinguishing and choosing between different objects, animals and situations such as working out who is helpful or who might cause them harm.

Understanding social relationships and the behaviour of other individuals.

\section{History of animal sentience}

Animals are conscious beings capable of feelings such as pain, pleasure and suffering.
Ancient thinkers Plutarch, Hippocrates and Pythagoras were all advocates for the fair treatment of animals. Their urgings were based on their understanding of the capacity of animals to feel pain and suffer (Preece et al., 2002). During the renaissance period (14th-17th century), a number of perspectives were proposed which included the infamous view from Descartes, who saw animals as automata, incapable of feeling or suffering (Duncan et al., 2006). Descartes' way of thinking was soon overshadowed by the drive for intellect and reason that was characteristic of the 18th century and the age of the Enlightenment. This period saw great changes in how animals were viewed, with a number of philosophers discussing the ability of animals to suffer (Senior et al., 2008). Darwin often spoke about the capacity of animals to feel pain and their many similarities to the human animal. In the 1960's, the book "Animal Machines" was written. In her book, Ruth Harrison exposed the realities of intensive farming at the time and the suffering of the animals within them (Harrison et al., 1966). In response to this, the UK Government set up the Brambell Committee in 1965 , this looked specifically at the welfare of animals in farming systems. The committee understood the importance of sentience, and ensured that all assessments took in to account both the feelings and behaviour of the animals (Duncan et al., 2006). Since then, there has been a notable increase in the number of publications concerned with animal welfare and the recognition of sentience.

\section{How do we know that animals feel pain and other feelings}

While pain itself cannot be directly observed in another being (Balcombe et al., 2009), there is mounting scientific evidence to support the common assumption that animals suffer. Dr. Bernard E. Rollin, Distinguished 
University Professor at Colorado State University, explains that:

"The neural mechanisms responsible for pain behaviour are remarkably similar in all vertebrates" (Rollin et al., 2003). Pain relieving drugs control what appears to be pain in all vertebrates and some invertebrates. The natural pain-inhibiting systems found in the human body (such as endorphins) are very similar to those found in all other vertebrates.

Humans' capacity to feel pain is a method of survival that is likely to have been preserved during our evolution. "Given that the mechanisms of pain in vertebrates are the same, it strains credibility to suggest that the experience of pain suddenly emerges at the level of humans."

De Camp Professor of Bioethics at Princeton University, Peter Singer, argues that "it is surely unreasonable to suppose that nervous systems that are virtually identical physiologically, have a common origin and a common evolutionary function, and result in similar forms of behaviour in similar circumstances should actually operate in an entirely different manner on the level of subjective feelings." While animals cannot verbally report their feelings as humans do, all other methods of studying human emotions can also be applied to animals (These measures have shown that many animals have "rich and deeply emotional lives" (Bekoff et al., 2007), while much attention is given to negative feelings such as stress and fear, animal welfare is also dependent on pleasurable emotions (Webster et al., 2005). Play behaviour is widespread in mammals and many birds. Young calves often have playful fights and prance about, while young chickens jump around and flap their wings for fun (Appleby et al., 2004). Animals also find pleasure in the search for and consumption of food, tactile interactions like grooming, sexual activity and basic comforts like basking in the sun. Today, millions of animals are denied the freedom to experience these basic pleasures because they are confined in cages, kept in isolation or crowded in sheds without access to a natural environment.

\section{Pain}

Psychologists usually define the pain that humans feel as a deeply unpleasant experience affecting the senses and the emotions. The bodies of vertebrates have most of the features which are involved in awareness of pain and therefore it would seem that conditions which cause pain to humans will also cause pain to animals. The great majority of scientists accept that animals feel pain and should be protected from it. Some animals who are at risk from predators, such as sheep and cattle may try to hide pain and distress because showing weakness puts them at greater risk so they may feel pain but not act as though they are suffering. Animal behaviour experts use a range of indicators to judge whether an animal is in pain. They look at how the animals behave whether they try to avoid using an injured limb, their cries, changes of mood, unresponsiveness and their reaction to pain relieving drugs. Confined and crowded animals often display disturbed behaviour and can injure each other. Rather than address the root causes producers may routinely mutilate their animals often without anaesthetic. This includes the debeaking of poultry, castration and tail docking of piglets. The screams of a castrated piglet suggest he is experiencing considerable pain (Fraser and Broom, 1997). Lame meat chickens that have difficulty walking choose feed that contains a pain-killing drug (Danbury et al., 2000). A study of a commercial strain of chickens found that nearly 30 per cent of chickens had difficulty walking and over three per cent could barely walk (Knowles et al., 2008). In a 
study (Gleerup et al., 2017) investigated pain face evaluations, using the bovine (Bos taurus) pain face and for this Forty-one $B$. indicus bulls underwent halothane-anaesthesia allocated to four groups: one non-surgical group $(\mathrm{n}=5)$, and three castration treatment groups: CL, intratesticular and subcutaneous lidocaine $\quad(n=12), \quad \mathrm{CM}, \quad$ subcutaneous meloxicam $(n=12)$ and $C$, no analgesia $(n=12)$. The animals were observed before anaesthesia (t0) and after anaesthesia (t1, t2, $\mathrm{t} 3$ and $\mathrm{t} 24$ ) by the same observer (blinded to treatment), trained to evaluate the bovine pain face (B. taurus). The face was evaluated as a whole as described for B. taurus but an intensity score was added to the pain face evaluation using a simple descriptive pain face intensity scale where $0=$ no pain face, $1=$ mild intensity, $2=$ moderate intensity, $3=$ severe intensity. All ratings were performed by visual inspection from the distance through binoculars. Thirteen missing ratings were evaluated (blinded) from videos retrospectively. All animals scored 0 (no pain face) before anaesthesia. The non-surgical group scored 0 at every time point. For the castrated animals, the risk of receiving a pain face intensity score 2 or 3 during the first 24 hours following surgery was, $77 \%$ for group C, $80 \%$ for group CL and $53 \%$ for group CM. The results of this study indicate that, a direct pain face evaluation with an intensity score may be useful for quantifying pain in $B$. indicus cattle. In this study, the animals treated with pre-operative meloxicam (CM), had a lower risk of receiving a moderatesevere intensity pain face score during the first 24 hours, compared to the animals in the $\mathrm{C}$ and $\mathrm{CL}$ groups.

\section{Facial expressions}

Facial expressions have the potential to indicate psychological and emotional experiences in animals, and can provide information on temporal or stimuli specific reactions (Descovich et al., 2017). Facial expressions also have social, reproductive and health functions and can therefore be more broadly relevant to welfare assessment than exclusively as indicators of affective state and it was proposed that irrespective of the proximate causes of facial expressions which are primarily communication and affective state, facial muscle movements or changes in the frequency of such may be reliably linked to underlying welfare states. It is concluded that the measurement of facial behaviour in animals is a useful but infrequently used measure that complements existing tools in the assessment of welfare. Sheep could use images of faces displaying different emotional states as cues in a simultaneous discrimination task (Bellegarde et al., 2017) and for that photos of faces of four sheep in three social situations: two with a negative valence (social isolation or aggressive interaction) and a neutral situation (ruminating in the home pen). In a two-armed maze, sheep $(n=16)$ were then presented with pairs of images of the same familiar individual taken in the neutral situation and one of the negative situations. Sheep had to learn to associate one type of image from a pair with a food reward. Once they had reached the learning criterion, sheep then had to generalise the task to new pairs of images of different conspecifics displaying the same emotions as in the previous phase. For every run in the maze, the latency to choose an arm and the outcome of the choice (success or error) were recorded, as well as the total number of runs needed to learn the task (learning speed). Influence of the type of image rewarded and of the side of presentation of the rewarded image were analysed by linear mixed models and learning speed was analysed by Mood's median test. All sheep learned the task with images of faces. Sheep that had to associate a negative image with a reward learned faster that sheep that had to learn the neutral-reward 
combination. With the exception of sheep from the Aggression-rewarded group, sheep could generalise the discrimination task to images of new faces. Sheep chose an arm correctly more often and more quickly when the rewarded image was displayed on the right side suggesting the influence of a right hemisphere/left visual field bias in face-based perception of emotions and they suggested that sheep can perceive the emotional valence displayed on faces and that this valence affects learning processes.

\section{Fear, anxiety and stress}

Repeated and/or prolonged stressful situations can cause illness and suffering in farm animals. The result can be stomach ulcers, reduced fertility, heart disease, reduced immunity to infection and increased death rates. In farming, animals are often put in situations which cause fear, anxiety and distress. These emotions are unpleasant and can cause suffering. The challenge now is to put our modern knowledge of animal sentience into practice, by protecting the physical and psychological welfare of the billions of animals we farm worldwide through better farming systems which meet their needs, Startle response as a measure of fear, defined here as the behavioral and physiological response to a perceived threat in dairy calves (Adcock et al., 2017) and predicted that calves exposed to predator odor, a fear-eliciting stimulus, would have a higher startle magnitude, elevated heart rate and longer latency to feed in response to a sudden noise than calves exposed to the odor of a herbivore or water. Thirty-four calves were assigned to 1 of 3 treatments (coyote urine, deer urine, water) in a between-subjects design. Each calf was fitted with an accelerometer and heart rate monitor and tested individually in $10 \mathrm{~min}$ trials in a familiar arena on 3 consecutive days. A bucket feeder containing $500 \mathrm{ml}$ of milk replacer was secured to the side opposite the arena entrance. Immediately before the trial the odor was dispersed into the arena with fans. The startle stimulus burst of white-noise was delivered upon the calf's arrival at the feeder. We assessed treatment (coyote, deer, and water) and test day effects on startle magnitude and heart rate with linear mixed models using the restricted maximumlikelihood method and calf identity fitted as a random effect. The effect of treatment and test day on latency was modeled using a parametric survival model.

Correlations between variables were made using Spearman's rho. The magnitude of the behavioral startle response was higher in the coyote treatment than in both controls on the first day of testing (mean total acceleration on day 1\} SE: Coyote: 19\}15 g; Deer: 166 3 g; Water: 172$\} 8$ g; Treatment $\times$ Day: $\mathrm{F} 450=2.56, \quad \mathrm{P}=0.050)$. Calves exposed to coyote odor tended to take longer to return to the feeder following the sudden noise compared to control animals (mean \} SE: Coyote: 11\}5 s; Deer: 4• 32 s; Water: 4$\} 1$ s; Treatment: $X 2$ 2=8.32; $\mathrm{P}=0.016$; post-hoc tests: $\mathrm{P} \leq 0.086$ ).

The cardiac startle response did not differ between treatments (mean heart rate $\mathrm{SE}$ : Coyote: 164\} 6 bpm; Deer: 167\}6 bpm; Water: 177\} 6 bpm; F2, 30=1.29, P=0.290) nor days $(\mathrm{F} 2,52=0.02, \mathrm{P}=0.979)$. Startle magnitude and latency to return to the feeder were positively correlated (rho $=0.60$, $\mathrm{P}<0.0001)$ Unexpectedly, heart rate correlated negatively with both startle magnitude (rho $=-0.26, \mathrm{P}=0.019)$ and latency to return to the feeder (rho=-0.46, $\mathrm{P}<0.0001$ ), which suggests fear brachycardia - a defense mechanism characterized by a decrease in heart rate - may accompany the startle response. In conclusion, the results provide support for using the behavioral startle response as a measure of fear in dairy calves. 


\section{Frustration of natural behaviour}

Farm animals feel and show frustration when they are prevented from carrying out natural behaviour. Animals' responses to frustration show that they are aware of what they want to do and how they expect the world to be. Animals in confinement may react to longterm frustration and stress by carrying out apparently pointless, repetitive behaviours or 'stereotypies'. Many stereotypies look like the original behaviour that the animal was strongly motivated to perform - such as escaping from being confined, getting food or exercising over a large range but in the captive setting they appear useless and abnormal. Stereotypies include the pacing of confined zoo animals and the bar-biting, head-weaving and tongue rolling of sows confined to narrow sow stalls. Confined farmed fish are affected by stereotypies too (Sneddon et al., 2007). Maternal deprivation which affects very large numbers of farm animals may be a factor in stereotypic behaviour (Latham and Mason, 2008). Piglets and calves are abruptly removed from their mothers at a very young age. Commercially farmed poultry are artificially incubated and never see their parents or other adults of their species while growing.

\section{Pleasure and play}

Animals also enjoy positive emotions from carrying out natural behaviour. Many of the skills that animals need in their adult lives in nature are partly learned by play activities when young. The fact that young farm animals clearly enjoy playing is a hallmark of their complex mental life.

\section{Sentient animals have complex social lives involving communication, organized groups and family bonds}

Cows are extremely social animals that live in small herds, forming social hierarchies and friendship pairs (Fraser and Broom, 1996). Chickens share information with specific calls to communicate their frustration, the discovery of food or the presence of a predator, suggesting some level of language (Millman and Duncan, 2001). Familiar pigs greet each other by touching noses and grunting, while those with close bonds may groom each other (Wood et al., 2006). Young piglets separated from their mothers give distinctive and frequent squeals to call her (Weary and Fraser, 1997). Dairy cows develop a strong maternal bond with their calf after as little as five minutes of contact after birth (Hudson and Mullord, 1977) and become stressed when their four-day old calf is removed (Sandem and Braastad, 2005). Mixing unfamiliar cows can cause a tenfold increase in conflict between the animals. Chickens in large flocks (up to 60,000 can be housed in a single shed) can constantly try to establish a social hierarchy without ever achieving it, while overcrowding can cause feather pecking and cannibalism amongst the birds (Mench and Keeling, 2001).

\section{Sentience and animal welfare}

Scientific investigations into animal welfare gradually increased in the late 1960s, following the publication of Harrison's book "Animal Machines" and the follow-up British government investigation published as the socalled "Brambell Report" (Command Paper $2836,1965)$ it was generally assumed that welfare would be intimately connected with the physiological stress response (Bareham et al., 1972, Bryant et al., 1972 and Gush et al., 1975). An animal that was stressed would have poor welfare and an animal that was not stressed would have good welfare. However, it is worth pointing out that it was the suffering of animals in intensive agriculture, in biomedical research and in product testing that spurred Harrison to write her book. It was 
not just the fact that these animals were stressed that troubled her; it was the fact that they were sentient and could feel stressed. The Brambell Committee also acknowledged that sentience was important. They stated, "Welfare is a wide term that embraces both the physical and mental well-being of the animal. Any attempt to evaluate welfare, therefore, must take into account the scientific evidence available concerning the feelings of animals that can be derived from their structure and functions and also from their behaviour" (Command Paper 2836, 1965). So the Brambell Committee also realised that an understanding of sentience is an essential part of assessing welfare. Through the 1980s, and triggered by the publication of Dawkins' book “Animal Suffering" (Dawkins et al., 1980), behavioural scientists gradually accepted the importance of feelings in their investigations into animal welfare problems. There was a progression from a position in which feelings were seen as a necessary component of welfare (Dawkins et al., 1980; Dawkins et al., 1990; Duncan et al., 1981; Duncan and Dawkins, 1983) to one in which feelings are the only thing that matters (Duncan, 1996; Duncan, 2004).

Acceptance of the fact that welfare is all to do with feelings brings with it a huge, almost insurmountable problem, which is that we can never prove conclusively that any organism is sentient. Subjective feelings are just thatsubjective and available only to the animal experiencing them. Fortunately, in the animal welfare debate we do not need to know exactly what an animal is experiencing. An indication of how positive or negative the animal is feeling would be extremely useful. For example, if we are considering a chicken that we suspect is frightened, we do not need to know if it is experiencing what a human being experiences when being threatened by a savage dog or being trapped in a burning building. In order to assess the chicken's welfare, all we need to know is whether or not it is experiencing something negative. If the chicken is experiencing negative feelings, it would also be helpful to know how negative these feelings are. Although it is impossible to measure feelings directly it is possible to get some indication of what an animal is feeling by indirect means.

Cognition usually refers to mental processes such as perception, memory, learning, computational skills, expectation etc. In other words, these are processes that have evolved to help the animal deal with the external world in a flexible way. Consciousness, on the other hand gives the animal information about its internal environment. Consciousness may be similar to an "inner eye" that allows the animal awareness of certain inner states such as fear and pain (Humphrey, 1986; Humphrey, 1992). In any investigation into how animals feel, it may be necessary to involve cognitive processes (Can an animal learn to avoid a frightening stimulus, can an animal remember a rewarding experience).There may also be interesting interactions between emotions and cognition (Paul et al., 2005). However, it should be remembered that it is the animal's awareness of what is happening that is crucial for its welfare, and in investigations into welfare we should be striving for measures (Albeit indirect measures) that give some indication of how positive or negative the animal feels.

It is possible to investigate feelings by indirect methods such as preference testing, motivational testing and understanding animal communication. Preference testing was pioneered by Hughes and Dawkins, both working with domestic fowl (Hughes and Black, 1973; Hughes et al., 1975; Hughes et al., 1977; Dawkins et al., 1976; Dawkins et al., 1977 and Dawkins et al., 1978). According to this method, the animal is given a choice of aspects of its environment and we 
assume that it will choose in the best interests of its welfare. There are certain pitfalls to be avoided when using preference tests. Despite all their limitations, preference tests give a good first indication of what the animal feels about various aspects of its environment. But a preference test is only the first step in investigating how an animal feels about its environment; it is also necessary to know how important a particular choice is. Even a consistent choice in one direction may not be important for the animal if, say neither choice results in suffering. But a choice may also represent the lesser of two evils with the animal suffering with both options. For these reasons, it is necessary to measure the strength of the preference as a follow up to preference testing.

There are various methods being used to measure strength of preference and an economic analogy is often used in the description of these methods (Mason et al., 1998). For example, we can "increase the price" of the commodity that the animal is choosing. This is done by seeing how hard the animal will "work" in order to obtain its preferred choice. Obstruction tests, in which the animal has to push past an obstruction or push open a weighted door in order to reach its preferred choice, is a common method (Nicol and Guildford, 1991; Mason et al., 2001). Operant responding is another common method being used to measure motivation (Dawkins and Beardsley, 1986). It is ironic that the operant conditioning chamber or "Skinner box" developed by behaviourists who campaigned so strongly against giving any consideration to feelings (Skinner et al., 1975), is now being used to investigate these very subjective feelings in an indirect way. Rather than "increasing the price" of a commodity, it is also possible to investigate motivation by reducing an animal's "income", although this is rather stretching the economic argument. The time that an animal has available to perform its various activities can be regarded as "income". The available time can be reduced until there is insufficient time for the animal to perform its full repertoire of behaviour. When this point is reached it is assumed that the animal will perform the activities that are really important to it and that other, less important activities will be omitted.

Of all the states of suffering, pain is probably responsible in animal agriculture for a bigger reduction in welfare than any other (Benson $e t$ al., 2004). Many farm animals are injured through living in ill-designed environments. For example, sows housed in dry sow stalls often have pressure sores on their hips from lying on hard surfaces, hens in battery cages often have hyperkeratosis of their feet pads from continually slipping on sloping floors and dairy cows often have feet and hock injuries from standing and lying on hard surfaces. Injuries also arise from social interactions such as fighting, tail-biting and feather-pecking. In addition, there are lots of surgical interventions, such as castration, taildocking, dehorning, teeth-trimming, beaktrimming, de-snooding and de-toeing all carried out without analgesic or anaesthetic cover. Then there are procedures, carried out for identification purposes such as eartagging, ear-notching and branding that could be painful. Finally, the poultry and swine sectors are running into fast-growth problems such as skeletal weaknesses, and the dairy sector is experiencing metabolic problems all of which could be painful (Benson et al., 2004).

Asking animals if they are experiencing pain, is much more of a challenge than asking them about other feelings. We can use an animal's tendency to avoid as a measure of its fear and we can use its tendency to approach as a measure of how motivated it is to gain access to some environmental feature. Looking very 
carefully at the behaviour of animals with and without analgesics can give some indication (Duncan et al., 1990; Molony and Kent, 1997). In a very exciting development of this method, it has been found that broiler chickens are capable of self-administering a pain-killing drug. When given a choice between two feeds, one of which contained a pain-killer, lame broilers ate more of the drugged feed than did broilers with no lameness. Moreover the walking ability of the lame birds was improved by this selfadministered treatment (Danbury et al., 2000).

Another possible route for gaining information about what animals may be feeling is through an understanding of their systems of communication as the severity of pain experienced by piglets during castration by carefully analysing their vocalizations (Weary et al., 1998; Taylor and Weary, 2000).

\section{Difficulty of measuring or proving sentience}

One of the key issues with understanding sentience and demonstrating its existence at a scientific level is that the concept relates to a being's own thoughts, feelings and emotions. The problem is however we cannot know exactly what or how another is feeling (Dawkins et al., 2001). This applies to both humans and animals and means that it can be difficult to ultimately prove the capacity for sentience. This is particularly difficult for animals as they lack the power of speech to convey their feelings. As a result, sentience is often described as anthropomorphic assumptions and its credibility as a science has suffered. This has had negative impacts on the development of the science and our understanding of sentience. Scientists in the field are often hindered by this and continue to seek unquestionable proof of sentience in animals. However, because sentience is characterised by personal phenomena and it cannot be known with absolute certainty what another is feeling it does not lend itself to this type of rigorous analysis.

Sentience and Anthropomorphism: Another of the key limitations to the acceptance and development of the science of animal sentience is the fear of anthropomorphism; the attribution of human characteristics to an animal. The concern over anthropomorphism really began following the behaviourist movement, when there was a drive to think of animals only in terms of behaviour and to not attribute any subjective feelings or experiences to them (Kennedy et al., 1992). Some avoidance of anthropomorphism is necessary as misuse can undermine the science of sentience however, complete avoidance of anthropomorphism can also be unhelpful and in many ways impossible. Our anthropomorphic tendencies may even be an innate part of our hereditary make-up. The ability to predict and control the behaviour of other animals may have been an advantage selected for in natural selection. Anthropomorphism appears to be unavoidable because not only is it a part of us culturally, hereditarily or both it is also apparent and often necessary in how humans make sense of and relate to animals.

Sentience and Cognition: The attribution of sentience to animals can also be hindered by the common misconception that the capacity for sentience is linked in some way to a species' cognitive ability. Cognition refers to the mental action or processes by which animals perceive process and store information (Dawkins et al., 2001). Sentience, on the other hand, refers to the capacity of an animal to have feelings and to be aware of a variety of states and sensations such as pleasure and suffering (Broom et al., 2007). It is often assumed that cognition and sentience 
are inextricably linked in that cognition automatically implies sentience. Indeed, evidence of higher cognitive abilities such as theory of mind and language has previously been used as a basis for advocating for the rights of certain species such as the great apes (Cavalieri and Singer, 1993). Cognition is not actually a prerequisite for sentience and it can be demonstrated independently (Dawkins et al., 2006).

Developing our understanding of animal sentience is imperative for improving animal welfare and attitudes towards animals. Concentrating on filling the gaps in our knowledge, humanely and reliably is essential given the extent of human impact on animals. With increasing attention on animal sentience science and the further development of humane approaches the future of the science of animal sentience is looking ever more promising and as a result so does the treatment of animals.

\section{References}

Appleby MC and Joy A. 2004. Mench and Barry O. Hughes. Poultry Behaviour and Welfare (CABI Publishing) 137.

Balcombe J. 2009. Animal pleasure and its moral significance. Applied Animal Behaviour Science. 208-209.

Bareham JR. 1972. Effects of cages and semiintensive deep litter pens on the behaviour adrenal response and production in two strains of laying hens. British Veterinary Journal. 128: 153163

Bellegarde L, Erhard HW, Weiss A, Boissy A and Marie J. 2017. Facial expressions of emotion influence sheep learning in a visual discrimination task. In the proceedings of the $51^{\text {st }}$ congress of the international society for applied ethology, 07-10, August, 2017, AarhmDenmark. Pp. 166.
Benson GJ and Rollin BE. 2004. Pain in Farm Animals: Nature, Recognition, and Management, Blackwell Publishing, Ames, Iowa. 61-84

Bernard E. 2003. 'Animal Pain' in Susan J. Armstrong and Richard G. Botzler (eds), the animal ethics reader (Routledge) 86.

Broom DM. 2007. Cognitive ability and sentience: Which aquatic animals should be protected? Dis. Aquat. Org. 75:99-108.

Bryant MJ. 1972. The social environment: behaviour and stress in housed livestock. Veterinary Research. 90: 351359

Cavalieri P, Singer P. 1993. The Great Ape Project: Equality beyond Humanity. Fourth Estate; London, UK.

Command Paper 2836. 1965. Report of the Technical Committee to Enquire into the Welfare of Animal Kept under Intensive Livestock Husbandry Systems. Her Majesty's Stationery Office, London.

Dawkins FM. 1990. From an animal's point of view: motivation, fitness, and animal welfare. Behavior Brain Science. 13: 161.

Dawkins MS. 1977. Do hens suffer in battery cages. Environmental preferences and welfare. Animal Behaviour. 25: 10341046

Dawkins MS. 2001. Who needs consciousness. Animal Welfare. 10: 1029.

Dawkins MS. 2006. Through animal eyes: What behaviour tells us. Applied Animal Behaviour Science. 100: 4-10.

Dawkins MS. Welfare and the structure of battery cages: Size and cage floor preferences in domestic hens. British Veterinary Journal. 134: 469-475

Duncan I. 2006. The changing concept of animal sentience. Applied Animal Behaviour Science. 100: 11-19. 
Duncan IJH and Dawkins MS. 1990. The problem of assessing 'well-being' and 'suffering' in farm animals. Research Veterinary Science. 50: 200-203

Duncan IJH. 1981. Animal rights - animal welfare: a scientist's assessment. Poultry Science. 60: 489-499

Duncan IJH. 1987. The welfare of farm animals: an ethological approach. Science Programme (Oxford), 71: 317326

Duncan IJH. 1996. Animal welfare defined in terms of feelings. Acta Agri. Scand., Sec. A, Animal Science Suppl. 27: 2935

Duncan IJH. 2004. A concept of welfare based on feelings. G.J.Benson, B.E. Rollin (Eds.), The Well-Being of Farm Animals: Challenges and Solutions, Blackwell, Ames, Iowa. 85-101

Fraser A and Broom D. 1996. Farm Animal Behaviour and Welfare (CABI Publishing, 3rd ed.).

Gary F. 2012. Sentience. Animal Rights: The abolitionist approach.

Harrison R. 1964. Animal Machines. Vincent Stuart, London.

Harrison R. 1966. Animal Machines: The New Factory Farming Industry. Vincent Stuart Publishers Ltd.; London, UK.

Hughes BO and Black AJ.1973. The preference of domestic hens for different types of battery cage floor. British Poultry Science. 14: 615-619

Hughes BO. 1975. Spatial preference in the domestic hen. British Veterinary Journal. 131: 560-564

Hughes BO. 1977. Selection of group size by individual laying hens. British Poultry Science. 18: 9-18

Humphrey N. 1992. A History of the Mind: Evolution and the Birth of Consciousness. Springer-Verlag, New York.

Kennedy J. 1992. The New Anthropomorphism. Cambridge
University Press; Cambridge, UK.

Latham NR and Mason GJ. 2008. Maternal deprivation and the development of stereotypic behaviour. Applied Animal Behaviour Science. 110: 84-108

Lehmann, Johnson CB and Michael L. 2017. Pain face intensity for quantification of pain in Bos indicus bull calves. In the proceedings of the $51^{\text {st }}$ congress of the international society for applied ethology, 07-10, August, 2017, AarhmDenmark. Pp-155.

Mason G, Cooper J and Clarebrough C. 2001. Frustrations of fur-farmed mink. Nature. 410: 35-36.

Mason G, Farland D and Garner J. 1998. A demanding task: using economic techniques to assess animal priorities. Animal Behaviour. 55: 1071-1075

Mench J and Linda JK. 2001. Social Behaviour of Domestic Birds' in L.J. Keeling and H.W. Gonyou (eds), Social Behaviour in Farm Animals (CABI Publishing) 194-8.

Nicol CJ and Guildford T. 1991. Exploratory activity as a measure of motivation in deprived hens. Animal Behaviour. 41: 333-341

Paul ES, Harding EJ Mendl M. 2005. Measuring emotional processes in animals: the utility of a cognitive approach. Neuroscience Biobehaviour Rev. 29: 469-491

Pearson SC. 2000. Self-selection of the analgesic drug Carprofen by lame broiler chickens. Veterinary Rec. 146: 307-311.

Preece R. Awe for the Tiger, Love for the Lamb: A Chronicle of Sensibility to Animals. Routledge; London, UK: 2002.

Ruth N and Janice S. 2001. Breaking Social Bonds in L.J. Keeling and H.W. Gonyou (eds), Social Behaviour in Farm Animals (CABI Publishing) 307310. 
Sandem A and Braastad B. 2005. 'Effects of Cow-Calf Separation on Visible Eye White and Behaviour in Dairy Cows A Brief Report'. Applied Animal Behaviour 95: 233.

Sarah JJ, Adcock and Cassandra B. 2017. The startle response as a measure of fear in dairy calves. In the proceedings of the $51^{\text {st }}$ congress of the international society for applied ethology, 07-10, August, 2017, Aarhm-Denmark. Pp-195.

Senior MA. 2008. Cultural History of Animals in the Age of Enlightenment. Berg Publishers; London, UK.

Skinner BF. 1975. The steep and thorny path to a science of behaviour. R. Harre (Ed.), Problems of Scientific Revolution, Oxford University Press, Oxford.

Smidt D (Ed.), Indicators Relevant to Farm Animal Welfare, Martinus Nijhoff, The Hague (1983), pp. 13-24

Sneddon L. 2007. Fish Behaviour and Welfare. Applied Animal Behaviour Science 104:173-175

Susan J, Hudson and Mullord MM. 1977. Investigations of maternal bonding in dairy cattle. Applied Animal Ethology. 271-276.

Suzanne TM and Ian H. 2001. Social Cognition of Farm Animals in L.J. Keeling and H.W. Gonyou (eds), Social Behaviour in Farm Animals (CABI Publishing), 373, 389-390.
Taylor AA and Weary DM. 2000. Vocal responses of piglets to castration: identifying procedural sources of pain. Applied Animal Behaviour Science. 70: pp. $17-26$

Weary DM and Fraser D. 1997. 'Vocal Response of 'Piglets to Weaning: Effect of Piglet Age'. Applied Animal Behaviour. 54: 53-160.

Weary DM, Braithwaite LA and Fraser D. 1998. Vocal responses to pain in piglets. Appl. Animal Behaviour Science. 56: 161-172.

Webster J. 2005. Animal Welfare: Limping Towards Eden (Universities Federation for Animal Welfare.) 11.

Webster J. 2005. Animal Welfare: Limping Towards Eden (Universities Federation for Animal Welfare.) 41.

Wood DGM, Duncan IGH and Fraser D. 1975. Social stress and welfare problems in agricultural animals. E.S.E. Hafez (Ed.), The Behaviour of Domestic Animals (3rd ed.), Williams and Wilkins, Baltimore. pp. 182-200

Wood-Gush. 2006. 'Introduction to Social Structures Communication' in Elements of Ethology (Chapman \& Hall, 1983), cited in Jacky Turner, Stop - Look Listen: Recognising the Sentience of Farm Animals (Compassion in World Farming Trust, updated version).

\section{How to cite this article:}

Suresh Kumar, Sanjay Choudhary, Rohit Kumar, Alok Kumar, Prasanna Pal and Kanika Mahajan. 2019. Animal Sentience and Welfare: An Overview. Int.J.Curr.Microbiol.App.Sci. 8(08): 635-646. doi: https://doi.org/10.20546/ijcmas.2019.808.074 